\section{INTRODUCCIÓN: FRONTERAS MORALES IMPORTANTES EN BIOÉTICA. ¿PUEDEN GUIARNOS NUESTRAS EMOCIONES?}

\author{
Stuart Youngner \\ Department of Bioethics, Case Western Reserve University, \\ Cleveland, Ohio \\ sxy2@cwru.edu
}

\begin{abstract}
Cómo citar este artículo/Citation: Youngner, S. (2013). "Introducción: fronteras morales importantes en Bioética. ¿Pueden guiarnos nuestras emociones?". Arbor, 189 (763): a064. doi:
\end{abstract} http://dx.doi.org/10.3989/arbor.2013.763n5001

Recibido: 13 julio 2012. Aceptado: 6 junio 2013.

El problema de las fronteras morales aparece desde los primeros escritos religiosos y filosóficos hasta las actuales guerras culturales en Estados Unidos y en otros países. Traspasar, eliminar o incluso desdibujar ciertas fronteras morales se considera frecuentemente como algo incorrecto o pecaminoso. La bioética se ocupa de las fronteras morales que aparecen en la esfera de la medicina y la ciencia biomédica.

No siempre se puede establecer una equivalencia entre las fronteras morales y las fronteras físicas, biológicas, sociales y legales con las cuales aquellas están asociadas. En bioética, un ejemplo de este tipo de fronteras lo constituye la línea que distingue al hombre de la mujer, al humano del animal, al humano de la máquina, la vida de la muerte, lo natural de lo artificial, al sí mismo del otro, la salud de la enfermedad y al matar del dejar morir. Los autores de este monográfico analizan algunas de estas fronteras. Me gustaría plantear estas discusiones examinando en primer

\section{INTRODUCTION: IMPORTANT MORAL BOUNDARIES IN BIOETHICS: CAN OUR EMOTIONS GUIDE US?}

Copyright: (C) 2013 CSIC. Este es un artículo de acceso abierto distribuido bajo los términos de la licencia Creative Commons Attribution-Non Commercial (by-nc) Spain 3.0. lugar en qué consiste la categoría general de las fronteras e interrogando el modo en que son definidas y mantenidas. En segundo lugar, exploraré brevemente los motivos potenciales que se pueden ofrecer, tanto para transgredir como para respetar las fronteras. Tal vez esta taxonomía pueda contribuir a la discusión general sobre las fronteras que tendrá lugar en los capítulos que siguen a esta introducción. Terminaré argumentando que las fronteras en gran medida son construcciones sociales, que pueden constituir importantes puntos de referencia normativos, aunque no necesariamente. Al establecer mi taxonomía, ofreceré varios ejemplos breves.

Para responder a la cuestión acerca de cuándo traspasar una frontera constituye también una trasgresión moral, ubicaré mi punto de vista en las democracias liberales, pluralistas y, en el mejor de los casos, comprometidas con ambas cualidades. Al asumir este punto de vista, rechazaré los argumentos puramente 
religiosos y también los procedentes de la llamada ley natural, razonando que el discurso racional y secular y la consideración de las pruebas empíricas son los únicos modos sensatos de llegar a acuerdos ante cuestiones acuciantes de biopolítica. También debemos tener en cuenta el campo en expansión de la sociobiología evolutiva, que ofrece toda una nueva visión sobre cómo las fronteras pueden haberse formado y por qué son mantenidas. Ahora bien, aunque no debamos postrarnos ante ningún dogma, superstición, tradición fundamentalista ni ante la simple y llana ignorancia, toda creencia debe ser tenida en cuenta cuando lo que está en juego es la construcción de una política social prudente.

¿Cómo se dibujan y se mantienen las fronteras? La palabra "frontera" generalmente evoca una imagen geográfica -alguna línea física o muro que separa esta parte de aquella-. Las fronteras geográficas son físicas y las establecen la tradición, los tratados y la ley. Puede tratarse de fronteras entre países, provincias, ciudades o barrios. Aunque las razones para establecer este tipo de fronteras pueden ser controvertidas - como, por ejemplo, las fronteras entre Israel y Palestina- existe una línea que los cartógrafos, con la ayuda de instrumentos de medida, fotos de satélite y sistemas GPS, pueden identificar con precisión. Ellos son los expertos y esta una cuestión científica. (Por supuesto, una cuestión bien diferente es dónde debería estar la frontera entre Israel y Palestina).

¿Cómo se identifican y localizan específicamente las fronteras no geográficas? ¿Quiénes son los expertos merecedores de la confianza para "vigilar" esas fronteras? ¿Cómo localizan esos expertos exactamente el lugar en que esa frontera se encuentra, para que los demás podamos determinar con precisión a qué lado de la misma nos encontramos?

Si somos informados, podemos decidir no pisar una frontera o, suponiendo que ya la hemos cruzado, volver atrás. En este punto las cosas no están tan claras, sino que varían dependiendo de cada tipo de frontera que nos ocupe. La "pericia" que sirve para delinear una frontera tal vez no sea la misma capaz de explicar por qué cruzarla es correcto o incorrecto, aunque aquella pueda ser usada para manipular este último aspecto: relocalizar una frontera suele servir para resolver o agravar dilemas morales.

¿Es la ciencia médica la "guardiana de las fronteras"? En un momento en el que la ciencia, en particular la ciencia médica, ofrece tantos modelos explicativos para entender el mundo que nos rodea, no sorprende que confiemos en la ciencia para dibujar muchas fronteras importantes y relevantes para la bioética. Algunos ejemplos de ello lo constituyen la frontera entre la vida y la muerte, entre el hombre y la mujer, entre lo humano y lo animal o entre el humano y la máquina. Aquí, la ciencia parece ofrecer la más rigurosa de las metodologías. El conocimiento de la genética, podría pensarse, ofrece un método definitivo para diferenciar las especies - por ejemplo, los humanos de otros animales-. Pero en realidad, nuestro conocimiento de la genética podría más bien cuestionar la idea de que las fronteras entre las especies tan siquiera existen.

Otro ejemplo lo constituye la frontera entre la vida y la muerte. A la mayoría de las sociedades modernas les gusta pensar que la ciencia puede identificar una línea clara en este punto. Sin embargo, nuestra experiencia con la muerte en cuidados intensivos - donde los pacientes conservan varias funciones mientras que han perdido otras que les son mantenidas con máquinas - nos indica lo contrario. La mayoría de los investigadores que han tratado la cuestión han llegado a la conclusión de que localizar el momento de la muerte en una unidad de cuidados intensivos es ante todo una tarea filosófica o religiosa. La ciencia médica es secundaria porque mide, y a menudo con extrema precisión, qué funciones se han perdido y cuáles permanecen. Sin embargo, solo la filosofía o la religión pueden responder la pregunta fundamental: cuáles de esas funciones son esenciales, es decir, cuáles son aquellas cuya pérdida indica la transición del ser humano al cadáver.

Las implicaciones de la línea que separa la vida de la muerte no son en ningún otro contexto más importantes o controvertidas que en el de los trasplantes de órganos, puesto que extraer órganos vitales podría matar a los donantes "vivos". De ahí que la frontera biológica entre la vida y la muerte interactúe con otra frontera importante: la que separa al matar del dejar morir. Esta es una frontera descriptiva u ontológica. Una vez que se ha localizado la frontera entre matar y dejar morir (lo cual no es una tarea fácil, como se verá), la mayoría de las sociedades está de acuerdo en que las personas no deberían ser asesinadas al y para obtener sus órganos. No sorprende por lo tanto que, en el proceso de pérdida progresiva de las unidades funcionales del ser humano, las instituciones médicas de todo el mundo hayan querido identificar la muerte cuanto antes, pero tratando de preservar simultáneamente tantas funciones como sea posible para facilitar el trasplante. Esto último lo justifican, bien sea con argumentos filosóficos, bien sea con argumentos científicos, dependiendo de cuáles sean los que con 
mayor probabilidad acepte su audiencia. Por ejemplo, mientras que los bioéticos han usado una argumentación filosófica para defender o atacar la integridad del concepto de muerte cerebral, la Academia Pontificia de las Ciencias delegó esa tarea en los expertos neurólogos -en gran medida, porque toda tentativa de encontrar bases teológicas para defender esa idea los habría expuesto a un amargo conflicto sobre la muerte cerebral en el seno de la Iglesia Católica-.

¿Es la filosofía analítica la guardiana de las fronteras? Algunas líneas fronterizas en bioética no pueden ser delimitadas por la ciencia, porque son esencialmente conceptuales. Un ejemplo lo constituye el límite entre matar y dejar morir. La mayoría de las sociedades consideran importante establecer una distinción clara entre ambas prácticas, y muchos filósofos han dedicado grandes esfuerzos para justificar esa distinción, aunque han acabado zozobrando con ella en el horizonte de la alta tecnología médica aplicada al soporte vital. Cuando la vida es mantenida por máquinas y sofisticados medicamentos, el razonamiento es a menudo reduccionista porque los motivos y la intención de los protagonistas - los pacientes, los familiares y los profesionales de la salud- son frecuentemente ocultos, inconscientes, contradictorios o múltiples.

Otra línea divisoria, definida y defendida por los filósofos, es la que separa lo natural de lo antinatural o artificial. Aunque el comportamiento humano está enraizado sin lugar a dudas en nuestra estructura genética, en la biología, en la evolución y en el condicionamiento social, la decisión sobre la esencia de la naturaleza humana, y sobre cuáles de nuestros actos son "artificiales" a menudo ha recaído en manos de los filósofos.

¿Son la religión, la tradición y la fe ciega en la autoridad las guardianas de las fronteras? Durante mucho tiempo la religión ha servido como guardiana de fronteras. El Mandamiento "no matarás" sigue teniendo un poderoso influjo en la sociedad (a pesar de que casi todas las religiones han avalado el homicidio para sus propios fines). La ley natural, que condena ciertos actos por ir "contra la naturaleza" tiene sus raíces profundamente enterradas en creencias religiosas. Sin embargo, la creencia religiosa tiene sus limitaciones -en particular en las sociedades seculares, multiculturales y pluralistas-. Si mi dios sabe lo que es correcto y el tuyo no, tenemos un problema.

La fe ciega en la autoridad y la tradición también han ejercido de protectoras de las fronteras de forma omnipresente a lo largo de la historia. Pero la Historia también está llena de ejemplos de cómo esas demarcaciones han causado grandes sufrimientos e injusticia a las mujeres, los homosexuales y a cualquier raza o grupo étnico que tuvo la desgracia de encontrarse en el lado equivocado de la frontera en un mal momento. Lo que en otra época fue justificado como fronteras cuasi-sagradas, en la actualidad es identificado como sexismo, homofobia o racismo.

¿Por qué querríamos cruzar una frontera? Varias razones pueden llevar a las personas a querer cruzar una frontera. Una es la simple curiosidad humana y el amor a la aventura. Cruzar una frontera puede ser emocionante y también peligroso. En ocasiones, las personas quieren cruzar una frontera porque se encuentran en el lado equivocado de la misma - por ejemplo, las mujeres que buscan trabajos más atractivos o roles sociales que todavía siguen perteneciendo al "territorio" de los hombres-. Otras veces, las personas quieren cruzar fronteras para autorrealizarse - por ejemplo, cuando a un hombre le gustan los hombres y solo puede ser feliz siguiendo una forma de vida homosexual-. Para la bioética, la razón para cruzar fronteras, como ocurre con el uso de las células madre o con la creación de quimeras para la investigación, es curar enfermedades que nos causan a nosotros o a nuestros semejantes grandes sufrimientos.

Los capítulos de este volumen analizan diferentes fronteras: conceptuales, religiosas y biológicas. A medida que los vaya leyendo, ponga atención a sus propias reacciones cuando se cruce alguna frontera. Cuando perciba incomodidad u ofensa, examine las razones que le conducen a sentirlas. Sobre todo, al defender su propia posición, o cuestionar las de los autores que escriben aquí, intente emplear un lenguaje y conceptos que vayan más allá de visiones religiosas o culturales. Una forma posible de tratar los dilemas contemporáneos de bioética consiste en atrincherarnos en nuestras estrechas comunidades, intentar imponer lo que "sabemos" que es correcto a los demás - a menudo con una actitud de autovalidación moral-. Una forma mejor de hacerlo es apelando a la beneficencia, la libertad personal y la justicia social como el marco de toda deliberación moral. Si emprendemos este camino, tendremos la oportunidad de servirnos de pruebas empíricas para refrendar o abandonar nuestras posiciones. Podemos formular cuestiones que tienen respuestas en el mundo real, como por ejemplo: ¿Se daña o, por el contrario, se ayuda a las personas al transgredir las fronteras tradicionalmente establecidas? ¿Gracias a ellas, los individuos se encuentran realizados, o más bien sometidos? 
Que no confiemos en los textos escritos hace miles de años por personas que pudieron ser inteligentes pero que con seguridad ignoraban el mundo que les rodeaba por su miedo y su superstición; que no defendamos ciegamente las tradiciones antiguas, muchas de las cuales resultarán ser, en el crisol de la historia, erróneas y gratuitamente crueles, tampoco implica

NOTA: este número monográfico de Arbor forma parte de las actividades desarrolladas en el marco del proyecto Kontuz!: Los límites del principio de precaución en la praxis ético-jurídica contemporánea (Plan Nacional de I+D+i, Subprograma de Proyectos de Investigación Fundamental no Orientada - FFI2011- 24414). que debamos apresurarnos ciegamente en alcanzar "un mundo feliz". Más bien, deberíamos servirnos de las preocupaciones heredadas de nuestros ancestros así como de nuestras intuiciones, para formular preguntas complicadas, reunir pruebas, y deliberar juntos sobre qué daños o beneficios reales podría implicar introducir cualquier cambio en el status quo. 